Research

\title{
Family-assisted therapy empowered families of older people transitioning from hospital to the community: a qualitative study
}

\author{
Katherine Lawler ${ }^{\mathrm{a}}$, Nicholas F Taylor ${ }^{\mathrm{a}, \mathrm{b}}$, Nora Shields ${ }^{\mathrm{a}}$ \\ a School of Allied Health, Human Services and Sport, La Trobe University, Melbourne; ${ }^{\mathrm{b}}$ Allied Health Clinical Research Office, Eastern Health, Melbourne, Australia
}

\section{K E Y W O R D S}

\section{Physical therapy modalities}

\section{Caregivers}

Patient participation

Qualitative research

Aged

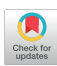

\begin{abstract}
A B S T R A C T
Question: What is the experience of patients and families participating in a family-assisted therapy intervention to augment physiotherapy in Transition Care? Design: Qualitative study using an interpretive description framework. Participants: Thirteen patients and 18 family members of patients in a Transition Care Program, who had participated in a family-assisted therapy intervention. Intervention: A 4-week family-assisted therapy program to augment usual physiotherapy care. Families were trained and supported by a physiotherapist to assist with safe and simple activities tailored to the patient's goals. Data collection and analysis: Semi-structured interviews were audio-recorded and transcribed verbatim. Researchers independently coded transcripts line by line, and themes and subthemes were derived inductively. Qualitative results were triangulated with quantitative outcomes from a concurrent randomised controlled trial. Results: The unifying theme was that family-assisted therapy empowered families in a healthcare setting. There were four subthemes: families made a complementary contribution to rehabilitation; familyassisted therapy brought physical and psychosocial benefits; simplicity, boundaries, training and support were important elements of the family-assisted therapy program; and implementation of family-assisted therapy requires a supportive policy and environment. Findings largely converged with quantitative outcomes from the randomised controlled trial. Conclusion: Family-assisted therapy to augment usual physiotherapy care was a positive and empowering experience for patients and families in Transition Care. This study indicates that family-assisted therapy may increase opportunities for physical activity and, importantly, engage family in a meaningful activity that gives them a genuine role in the healthcare team. Trial registration: ACTRN12616000565448. [Lawler K, Taylor NF, Shields N (2019) Family-assisted therapy empowered families of older people transitioning from hospital to the community: a qualitative study. Journal of Physiotherapy 65:166-171]
\end{abstract}

(C) 2019 Australian Physiotherapy Association. Published by Elsevier B.V. This is an open access article under the CC BY-NC-ND license (http://creativecommons.org/licenses/by-nc-nd/4.0/).

\section{Introduction}

Transition Care was introduced in Australia in 2004 following the advent of Intermediate Care in the United Kingdom. ${ }^{1}$ Transition Care is a publicly funded program that is available for up to 12 weeks. It provides older people who have been in hospital with time, nursing or personal care and low-intensity therapy, to assist their recovery and facilitate their return to community living. ${ }^{1}$ Unlike other existing rehabilitation services that have standards available to direct care and staffing levels, ${ }^{2}$ physiotherapists working in Transition Care have little guidance about how to deliver therapy. Physiotherapy staffing levels in Transition Care are low ${ }^{1}$ but patients often have impaired mobility and are facing their last opportunity to return home instead of being admitted to permanent residential care. ${ }^{3}$

One approach to providing physiotherapy in Transition Care could be family-assisted therapy. Engaging families in physiotherapy is an emerging area of research, ${ }^{4}$ particularly as a strategy to increase therapy dose. Higher doses of therapy have been associated with better outcomes, including strength after stroke ${ }^{5}$ and balance for adults receiving rehabilitation. ${ }^{6}$ Previous family-assisted therapy research has investigated augmenting physiotherapy for people after stroke, with results suggesting that this approach is safe; however, its effectiveness is unclear. ${ }^{7,8}$ Previous qualitative research in Transition Care has explored the prospect of family-assisted therapy and suggested that training families to augment interventions provided by physiotherapists could improve patient outcomes. ${ }^{9}$ However, it is believed that this approach has not been implemented and evaluated in a Transition Care setting or in any inpatient setting with adults aged $\geq 80$ years.

To understand the impact of a family-assisted therapy intervention in Transition Care, a mixed methods study was completed. Given the complexity of family relationships, the authors were aware that quantitative measures may not fully capture the impact of such a program. Therefore, a qualitative research study was conducted alongside a randomised controlled trial. ${ }^{10}$ This paper reports the outcomes of the qualitative study. 
Box 1. Semi-structured interview guide.

Topic

What was the overall experience of patients and family members?

\author{
Has family-assisted therapy \\ improved community \\ participation?
}

How does family-assisted therapy impact relationships?

Are there important questions the interviewer has not thought to ask?

\section{Participant questions and prompts}

Would you recommend this approach to other patients/family members in Transition Care? Prompts: things that worked, things that did not work, differences between therapist and family involvement, training and support needs

How confident would you be to go out with the family member/take the patient on an outing? Prompts: influence of family-assisted therapy

What kind of impact has this program had on your relationship with the patient or family member? Prompts: family conflict, caregiver stress, additional burden of program given current life stressors, enjoyment, role reversal

Is there anything else you would like to add? Prompts: considerations for future planning, other settings eg, acute
Therefore, the research question for this qualitative study was:

What is the experience of patients and families participating in a family-assisted therapy intervention to augment physiotherapy in a Transition Care setting?

\section{Method}

\section{Design}

The theoretical framework underpinning this study was interpretive description. Interpretative description seeks to find meaning relevant to clinical practice by describing and then applying theory from themes arising, with the goal of improving patient care or quality of life. ${ }^{11}$ Semi-structured interviews were conducted to provide a thorough understanding of participants' thoughts and experiences, to inform future research and clinical practice. Qualitative data were compared with quantitative data from a randomised controlled trial (conducted concurrently) ${ }^{10}$ for convergence and divergence. The Consolidated criteria for Reporting Qualitative research (COREQ) checklist ${ }^{12}$ was used to guide reporting.

\section{Participants}

The study was conducted in the Transition Care Program of a large metropolitan health service in Melbourne, Australia. This program includes 72 beds across a hospital ward and two nursing homes, and also provides transitional support to patients in their homes.

The participants were patients and family members of patients admitted to Transition Care. To distinguish between these two groups of participants, in this paper they are referred to as patients and family members, respectively. To be eligible for this qualitative study, participants had to have participated in a 4-week family-assisted therapy intervention, where families were trained and supported to provide therapy to augment usual physiotherapy care as part of the experimental group of a randomised controlled trial. ${ }^{10}$ Patients had to be able to converse in English, follow single-stage commands, and stand with no more than one assistant. Family members had to be physically fit, available to assist with therapy at least three times per week, and able to converse in English.

\section{Intervention}

The 4-week family-assisted therapy intervention was individualised according to each patient's expressed functional goals. Families were trained to assist with therapy that was considered safe for the family member to deliver, such as practice of transfers, walking, or simple exercises. Patients received an average of four family-assisted therapy sessions per week in addition to usual physiotherapy care. On average, this equated to a total of 226 minutes of family-assisted therapy over the 4 -week period. Family members received an average of 130 minutes of training and support from a physiotherapist over the 4-week period, including face-to-face contact, telephone calls, emails and text messages.

\section{Data collection}

Interviews were conducted at each participant's preferred location, including at their bedside or another quiet location in the ward, in their home or over the telephone. Unless they chose to be interviewed together, patients and family members were interviewed separately. Questions were focused on their experiences of the family-assisted therapy intervention. They were asked about: whether they would recommend this approach to others and why; their confidence with community participation activities; and the impact of family-assisted therapy on their relationship (Box 1).

\section{Data analysis}

Interviews were audio-recorded and transcribed verbatim. Participants could comment or make corrections on copies of their transcripts and the interviewer's interpretation of the main themes. This enabled participants to confirm that the transcribed words reflected their true thoughts, and that the initial interpretation was fitting. ${ }^{13}$ Emerging themes arising from earlier interviews were explored during interviews with participants recruited later, to further validate findings. ${ }^{11}$ After all interviews were completed, two researchers (KL and NS) conducted line-by-line coding of all transcripts, independently. One researcher (KL) coded transcripts using NVivo computer software ${ }^{\mathrm{a}}$ and the other (NS) using Microsoft Word. The two researchers then met and reviewed codes together and used inductive reasoning to group them into categories. They finally agreed upon themes and subthemes, which were then discussed with the third member of the team (NT). One researcher (KL) then re-read all transcripts to ensure that no key ideas had been missed. For the purposes of data presentation, patients were numbered P1, P2, etc, and family members were numbered F1, F2, etc. Where two family members of one patient participated, they were further labelled $a$ and $b$. In this way, each number identifies a family unit. 
Table 1

Characteristics of participants.

\begin{tabular}{|c|c|c|c|c|c|c|c|}
\hline \multicolumn{4}{|c|}{ Patient } & \multicolumn{4}{|c|}{ Family member } \\
\hline Identifier & Age $(y)$ & Gender & Primary diagnosis & Identifier & Age $(y)$ & Relationship & Employment status \\
\hline P1 & 89 & female & fall and fractured lower limb & $\mathrm{F} 1$ & 47 & son & self-employed \\
\hline P2 & 83 & female & deconditioning & F2 & 57 & daughter & unemployed \\
\hline P3 & 68 & male & stroke & F3 & 31 & daughter & part-time \\
\hline P4 & 82 & female & fall and fractured upper limb & F4 & 87 & husband & retired \\
\hline P5 & 80 & male & stroke & F5 & 54 & son & self-employed \\
\hline P6 & 92 & female & fall and fractured lower limb & F6 & 60 & daughter & part-time \\
\hline P7 & 84 & male & spinal surgery & F7 & 36 & daughter-in-law & family responsibilities \\
\hline P8 & 81 & female & revision of total hip replacement & F8 & 54 & nephew & self-employed \\
\hline P9 & 79 & male & deconditioning & F9 & 76 & wife & retired \\
\hline \multirow[t]{2}{*}{ P10 } & 81 & male & fall and fractured lower limb & F10a & 35 & son & full-time \\
\hline & & & & F10b & 27 & daughter-in-law & full-time \\
\hline P11 & 85 & female & fall and fractured pelvis & F11 & 55 & daughter & retired \\
\hline P12 & 83 & male & delirium & F12 & 53 & daughter & part-time \\
\hline \multirow[t]{2}{*}{ P13 } & 86 & female & fall and fractured lower limb & F13a & 47 & daughter & part-time \\
\hline & & & & F13b & 51 & daughter & part-time \\
\hline P14 & 70 & female & fall and fractured lower limb & F14 & 59 & brother & full-time \\
\hline \multirow[t]{2}{*}{ P15 } & 89 & male & deconditioning & F15a & 76 & wife & retired \\
\hline & & & & F15b & 59 & daughter & part-time \\
\hline
\end{tabular}

Patients with shaded identifiers did not participate in the interview; see main text for details.

\section{Rigour and trustworthiness}

Credibility, which is similar to internal validity, ${ }^{14}$ was demonstrated by using audio-recording and transcription of semi-structured interviews. ${ }^{13,15}$ The views of patients and family members were sought, to assist with triangulation of data. ${ }^{15}$ The findings were triangulated with quantitative data from the randomised trial. ${ }^{10}$ Member-checking was completed to ensure that the presented themes were an accurate representation of participants' thoughts. ${ }^{13}$ Dependability, which is similar to reliability, ${ }^{16}$ was addressed by keeping an audit trail of decisions made when collecting and analysing data. ${ }^{14}$ The use of thick, rich description of data enhanced dependability and transferability of results. ${ }^{14}$ Transferability was also strengthened by providing a detailed description of the participants and of the setting where this study was conducted.

\section{Research team and reflexivity}

The interviewer $(\mathrm{KL})$ was a physiotherapist working in a different part of the hospital. She had previously worked clinically in Transition Care and conducted interviews for a qualitative study in the same setting. ${ }^{9}$ Participants were known to the interviewer, as they had worked together over a 4-week period as part of the intervention. Therefore, rapport had already been established, which is important in interpretive description. ${ }^{11}$ Participants were encouraged to be frank and were informed that the investigators were keen to understand positive and negative thoughts and experiences. Participants were aware that the interviewer was an experienced physiotherapist, with an overall goal to improve care for older people in Transition Care. The other two researchers were physiotherapists with experience in qualitative research and rehabilitation and who worked at the university. The team had previously worked together on a qualitative research project in Transition Care. ${ }^{9}$

\section{Results}

\section{Flow of participants through the study}

There were 17 patients and 20 family members in the experimental group, of whom 13 patients and 18 family members participated in the qualitative study (Table 1), equating to $76 \%$ of the patients and $90 \%$ of the family members who participated in the randomised controlled trial. Interviews were an average of $10 \mathrm{mi}-$ nutes long (range, 4 to 26). Regarding the four patients who did not participate: two (and their two family members) did not participate as the patient was palliative or deceased, one was unable to participate in an interview due to cognitive impairment, and one had not received the intervention as allocated. Data saturation was demonstrated by no new themes presenting in the final six interviews.

\section{Main themes}

The unifying theme was that family-assisted therapy empowered families in a healthcare setting. There were four subthemes: families made a complementary contribution to rehabilitation; familyassisted therapy brought physical and psychosocial benefits; simplicity, boundaries, training and support were important elements of the family-assisted therapy program; and implementation of family-assisted therapy requires supportive policy and environment. A sample of the coding tree is presented in Appendix 1 (see eAddenda for Appendix 1).

\section{Family-assisted therapy empowered families in a healthcare setting}

The greatest impact of the intervention was described as empowering families, including both patients and family members, particularly in the context of their disempowering experience of hospitalisation. Empowerment was achieved in two main ways. First, training family members to have a specific role in the hospital setting countered the spoken and unspoken rule that family should not assist patients with movement. In what was perceived as an understaffed hospital environment, participating in family-assisted therapy empowered patients and their families toward action, freeing them to pursue their goals regardless of staffing levels:

I guess also it was nice that then it became acknowledged that we... were officially allowed to walk around and to assist Dad with some transfers and walking around the hospital. (F15b)

Second, the intervention empowered family members with practical knowledge and skills. The intervention gave family members tools to do something they perceived as meaningful. Family members were keen to know the 'right way to do things' (F9) so they could make a positive contribution toward the patient's recovery and do something other than chat about the weather.

The intervention empowered patients and family members in different ways. In some circumstances, the patient took the lead and harnessed the training provided to their advantage:

Sometimes [the trained family member] doesn't want to do it or she doesn't feel up to doing it, but if ever any of the family come I try and make a point of getting them to take me for a walk. (P2) 
In other cases, family members were pushing forward:

You know, having him involved, yes, I feel, you know, I've got to now behave myself and get really better because I'm part of his project. [laughs] (P8)

\section{Families made a complementary contribution to rehabilitation}

Family members added more than manpower (plugging gaps in an overburdened healthcare system); their roles were unique and complemented the role of health professionals. Families have a lifetime history with 'the patient', understanding their temperament and nature more than any health professional could. Families also play a critical role in motivating a patient towards achieving their goals and adhering to the advice of health professionals:

I think involving the family more is better, like they know the patient and what she likes and doesn't like or things she has difficulty with. (P6)

Family members contributed a range of skills and life experiences. Some were trained in healthcare, others were teachers and one worked in risk management. Some had direct experience of illness or injury to draw from:

I've had a few motorcycle accidents in my time and broken a few bones and while... I've never had exactly the injury that [the patient] had, I understood a bit of the cycles of recovery and stuff from a mental point of view... so I think I could actually help her a bit... (F14)

\section{Family-assisted therapy brought physical and psychosocial benefits}

Patients and family members described benefits associated with involvement in family-assisted therapy, including: support for family relationships; psychosocial benefits; and increased physical activity. Patients and family members described a sense of fun and togetherness, having a common goal that brought focus to visits and a reason to spend time together:

I also felt it gave him a reason to be focused and come here and, you know, and participate with me. Not that I didn't think he would come if he didn't do that, but I just felt it was a bit more encouragement for coming to see me sort of thing, so it had that extra purpose, other than the exercise it was also the social, additional social contact. (P14)

Patients and family members felt patients received psychological benefits. These benefits included building confidence and independence, a sense of hope and motivation, and feeling loved and supported in difficult times. These benefits were described as giving families a sense that things were improving, even though the circumstances were often difficult, as patients were walking a fine line between returning home or moving into long-term care.

But I think the really good thing for [the patient] was that she felt that it was assisting with her progress and that people cared... for her to feel that someone cared and was helping her and so on is a really big thing. (F14)

I've sort of really got that feeling yes home is in sight. Which I kept saying I'm going home but I knew that it was going to be tough, but I'm feeling in myself more confident about it. (P8)

Family members also spoke of achieving psychosocial benefits including improvements in their confidence:

I feel confident now about him going down and getting the bins and I don't really worry that he's gonna trip. (F3)

Another spoke of a reduction in stress:

It actually probably relieved a bit of stress because I saw him making progress and I was getting very worried that they were sort of trying to push him into an actual aged care facility which I know he's not ready for yet. (F10a)

Families also talked about the sense of achievement of assisting with exercise, stating:

it helps the families feel like they're actually doing something. Instead of just observing, they're actually part of the solution. (F1)

Patients and family members also noted the patients' increased physical activity. They were aware that sitting doing nothing was not beneficial and that movement was important. The intervention was focused on the patients' functional mobility goals, which often related to walking. Working towards these goals together was highly valued by participants. One patient mentioned:

it's certainly helped with the walking because otherwise I'd be... I'd have been just stuck in the one place. You can't sit all day doing nothing (P11).

Another stated:

I was getting that extra exercise, you know, that he was coming in and making sure that I did do the walking (P8).

Similar thoughts were expressed by families:

Once we got into the program, he could just literally get the kilometres into his legs and, yeah, he started making leaps and bounds within the first couple of weeks of being able to get out and walk every day with [us] (F10a).

\section{Simplicity, boundaries, training and support were important elements of the family-assisted therapy program}

One of the most mentioned program factors that supported the intervention's success was its simplicity:

I think the simplicity of it, like all you have to do is get up and go for a walk with your daughter, was really critical to making sure that she was actually happy to participate in it... if you'd sort of suggested three or four different types of exercises I think we both possibly might've thrown our hands up in the air and thought it was all a bit too hard. (F13a)

Participants considered boundaries around the program to be helpful by allowing it to fit with busy schedules or minimise stress. For example, participants were asked to spend at least three times a week exercising together but with emphasis on an achievable duration:

The exercises were not sort of particularly onerous timewise, it was really only a matter of sort of doing 10 or 15 minutes when we saw each other. (F13a)

Training and support from the physiotherapist were seen as essential. Family members expressed the value of face-to-face training to learn simple things such as how to position a walking frame or where to stand when helping with walking. Support was available and, although rarely accessed, its availability was highly valued:

I knew you're a phone call away if I had any questions, so that was a good thing to have at the back of my mind. (F3)

\section{Implementation of family-assisted therapy requires supportive policy and environment}

Contextual factors such as policy and the environment were described as ongoing challenges to integrating family-assisted therapy into usual practice. Contextual factors that support empowerment 
Table 2

Triangulation of results between qualitative study and randomised controlled trial for the unifying theme and two of the four subthemes.

\begin{tabular}{|c|c|c|c|}
\hline $\begin{array}{l}\text { Theme or subtheme } \\
\text { Code }\end{array}$ & Qualitative findings & Quantitative findings ${ }^{10}$ & Triangulation \\
\hline $\begin{array}{l}\text { Family-assisted therapy empowered } \\
\text { families in a healthcare setting }\end{array}$ & $\begin{array}{l}\text { Family members gained practical } \\
\text { knowledge and skills, and were } \\
\text { empowered to assist patients to achieve } \\
\text { their functional mobility goals. }\end{array}$ & $\begin{array}{l}\text { Compliance with trial method was high, with } \\
\text { patients receiving above the anticipated average } \\
\text { of three family-assisted therapy sessions per } \\
\text { week. }\end{array}$ & Convergent \\
\hline \multicolumn{4}{|l|}{$\begin{array}{l}\text { Family-assisted therapy brought physical } \\
\text { and psychosocial benefits }\end{array}$} \\
\hline \multirow[t]{2}{*}{ Psychosocial benefits to patients } & \multirow[t]{2}{*}{ Improved confidence and independence } & $\begin{array}{l}\text { The Short Falls Efficacy Scale - International } \\
\text { scores did not differ significantly between } \\
\text { groups (MD }-0.7 \text { units, } 95 \% \mathrm{CI}-3.0 \text { to } 1.7 \text { ). }\end{array}$ & \multirow[t]{2}{*}{ Divergent } \\
\hline & & $\begin{array}{l}\text { No significant differences were identified between } \\
\text { groups in quality of life measures: } \\
\text { EQ-5D-3L index MD } 0(95 \% \mathrm{CI}-0.2 \text { to } 0.1) \text { and } \\
\text { ICECAP-O tariff } 0 \text { ( } 95 \% \mathrm{CI}-0.1 \text { to } 0.1) \text {. }\end{array}$ & \\
\hline Psychosocial benefits to family members & $\begin{array}{l}\text { Improved confidence and no impact on } \\
\text { or reduction in stress }\end{array}$ & $\begin{array}{l}\text { Moderate observed effect size }(0.6,95 \% \mathrm{CI}-0.2 \text { to } \\
\text { 1.3) in favour of experimental group at Week } 5 \text { for } \\
\text { modified Caregiver Strain Index }\end{array}$ & Convergent \\
\hline Increased physical activity & More opportunities to move & $\begin{array}{l}\text { Large effect size favouring experimental group at: } \\
\text { - Week } 5 \text { for daily steps ( } 0.9,95 \% \text { CI } 0.1 \text { to } 1.7) \\
\text { - Discharge for Modified Barthel Index } \\
(0.8,95 \% \text { CI } 0.1 \text { to } 1.5)\end{array}$ & Convergent \\
\hline \multicolumn{4}{|l|}{$\begin{array}{l}\text { Implementation of family-assisted therapy } \\
\text { requires supportive policy and environment }\end{array}$} \\
\hline \multirow[t]{2}{*}{ Risk } & \multirow{2}{*}{$\begin{array}{l}\text { Risk led to policies unsupportive of } \\
\text { family-assisted therapy and families felt } \\
\text { there was too much emphasis on risk } \\
\text { in hospitals. }\end{array}$} & $\begin{array}{l}\text { No serious adverse events were reported, and } \\
\text { no falls occurred during } 249 \text { sessions of } \\
\text { family-assisted therapy. }\end{array}$ & \multirow[t]{2}{*}{ Convergent } \\
\hline & & $\begin{array}{l}\text { The experimental group had an observed falls } \\
\text { rate of } 78 \% \text { less than the control group (incidence } \\
\text { rate ratio } 0.22,95 \% \text { CI } 0.04 \text { to } 1.20, p=0.08 \text { ). }\end{array}$ & \\
\hline
\end{tabular}

were generally described as unfulfilled opportunities. For example, a collaborative approach from staff could be helpful, or encouragement for families to take opportunities to learn how to assist with walking, or simple environmental changes such as having chairs available to rest in between a ward and the kiosk. This was not limited to Transition Care but was seen as an opportunity throughout hospitalisation. The hospital's approach to risk was considered unsupportive of family-assisted therapy and described as overemphasised as part of a 'nanny state sort of thing' (F8). This thought was captured by a family member:

Families are quite willing to help, and they often are, and I think they should be allowed to do more if they want to... like families are very frightened to ask can they do something, and like sometimes people are very gung-ho and say no you can't because they're a high falls risk, blah, blah, blah. Whereas I think it would help an awful lot if they were allowed or encouraged more. (F6)

\section{Triangulation}

Qualitative and quantitative data were triangulated for the unifying theme and two subthemes (Table 2). There was convergence across all comparisons except for data relating to psychosocial benefits for patients. Quantitative data revealed no change in falls-related self-efficacy, but interview findings suggested that patients may have achieved increased confidence. It is possible that patients were not thinking about falls when discussing confidence.

\section{Discussion}

Involvement in family-assisted therapy was viewed positively by older people transitioning from hospital to the community, and their family members. Our qualitative data largely triangulate with quantitative data from a randomised controlled trial conducted concurrently, ${ }^{10}$ supporting the notion that this may be a useful approach to physiotherapy in Transition Care. The most important impact of this family-assisted therapy intervention was empowerment of families, with additional psychosocial benefits to patients and family members and increased physical activity for patients. These findings are consistent with participants in the same setting who were asked to consider the idea of family-assisted therapy, but had not participated in a family-assisted therapy intervention.

The trial was designed to improve physical outcomes for patients, but the most important finding was about empowerment of patients and families in an otherwise disempowering setting. Person-centred care is considered a cornerstone of healthcare but is difficult to achieve in practice. ${ }^{17,18}$ For example, nursing home regulations in some countries require residents and their families to be included in decision-making about their care plans. However, a Canadian study described how residents and families invited to care conferences were effectively excluded through process, content and devaluing knowledge. $^{19}$ Our study suggests that an alternative practical approach, such as family-assisted therapy implemented by physiotherapists, may help to overcome these challenges. However, like previous work, it also highlights the need to consider supportive policy and environment, including how risk is viewed and managed. ${ }^{17}$ A transitional care ward that offers all families the opportunity to engage in care, with consent from the patient, and to the extent that may suit each family's circumstances, ${ }^{20}$ may be a starting point.

This qualitative study provides important confirmation of quantitative data from the randomised trial ${ }^{10}$ and an earlier systematic review $^{21}$ suggesting that family engagement in care may not increase caregiver burden. Caregiver burden is a notable concern for family members caring for frail older people in the community. ${ }^{22}$ However, this study indicates that meaningful engagement in care as an adjunct to usual care, with training and support provided by a physiotherapist, may reduce rather than increase strain. Therefore, family-assisted therapy may be a feasible approach to increasing therapy dose for people in Transition Care. This will not necessarily be true for all, ${ }^{20}$ but the possibility of caregiver burden should not be a barrier to offering patients and families the opportunity. Each patient and family can decide for themselves what level of engagement will work for them.

This study was reported with reference to the COREQ checklist. ${ }^{12}$ Another strength was that it was part of a mixed methods trial, which provided the opportunity to triangulate concurrently collected qualitative and quantitative data. ${ }^{23}$ Also, eligibility criteria were broad and participants with cognitive impairment were included. ${ }^{24}$ The use of 
interpretive description enabled the study to be framed in such a way that clinicians and policy-makers have access to findings that may be applied to clinical practice. ${ }^{11}$ Interviews were relatively short, but rich data were shared, which may have resulted from the interviewer having developed rapport through delivering the family-assisted therapy intervention. The interviewer's involvement in the intervention may be considered a limitation, but the risk of bias or leading questions was mitigated by encouraging participants that sharing positive and negative experiences was helpful, and by triangulation with quantitative data. ${ }^{23}$

Older people transitioning from hospital to the community have limited access to physiotherapy. This study indicates that familyassisted therapy to augment usual physiotherapy care may increase opportunities for physical activity and, importantly, engage family in a meaningful activity that gives them a genuine role in the healthcare team. Further research could investigate this approach in other healthcare settings such as geriatric evaluation and management, general medical wards, or residential aged care facilities.

What was already known on this topic: Transition Care provides older people who have been in hospital with lowintensity rehabilitation and other interventions to assist their return to community participation. Involving the family to assist in providing greater opportunities for rehabilitation (family-assisted therapy) is favourably viewed by people in Transition Care and their families, but this research has been based on the idea rather than actual experience of family-assisted therapy.

What this study adds: Older people in Transition Care and their family members believed that family-assisted therapy empowered them to increase opportunities for physical activity, and that it provided physical and psychosocial benefits. Simplicity, boundaries, training and support were considered important elements of family-assisted therapy. The perceived benefits of family-assisted therapy were largely consistent with the quantative results from a concurrent trial of family-assisted therapy involving the same participants.

Footnotes: a NVivo computer software, version 11 2015, QSR International Pty Ltd.

eAddenda: Appendix 1 can be found online at: 10.1016/j.jphys.201 9.05.009.

Ethics approval: The Austin Health Human Research Ethics Committee, the Eastern Health Human Research Ethics Committee and the La Trobe Human Ethics Committee approved this study. All participants gave written informed consent before data collection began.

Competing interests: Nil.

Source(s) of support: This work was supported by an RM Gibson Research Fund Grant and an Australian Government Research Training Program Scholarship.

Acknowledgements: We thank the patients and families who participated in the trial, and staff in the Eastern Health Transition Care Program for their support of the project and assistance with recruitment

Provenance: Not invited. Peer reviewed.
Correspondence: Katherine Lawler; School of Allied Health, Human Services and Sport, La Trobe University, Melbourne, Australia. Email: katherine.lawler@utas.edu.au

\section{References}

1. Brusco NK, Taylor NF, Hornung I, Schaffers S, Smith A, de Morton NA Factors that predict discharge destination for patients in transitional care: a prospective observational cohort study. Aust Health Rev. 2012;36:430436.

2. Australasian Faculty of Rehabilitation Medicine. Standards for the provision of inpatient adult rehabilitation medicine services in public and private hospitals. Sydney: Royal Australasian College of Physicians; 2011.

3. Masters S, Halbert J, Crotty M, Cheney F. Innovations in Aged Care: What are the first quality reports from the Transition Care Program in Australia telling us? Australas J Ageing. 2008;27:97-102.

4. Lawler K. Family-led rehabilitation after stroke may not improve patient outcomes compared to usual care [commentary]. J Physiother. 2018:64:59

5. de Sousa DG, Harvey LA, Dorsch S, Glinsky JV. Interventions involving repetitive practice improve strength after stroke: a systematic review. J Physiother 2018;64:210-221

6. Treacy D, Schurr K, Lloyd B, Sherrington C. Additional standing balance circuit classes during inpatient rehabilitation improved balance outcomes: an assessorblinded randomised controlled trial. Age Ageing. 2015:44:580-586.

7. Vloothuis JD, Mulder M, Veerbeek JM, Konijnenbelt M, Visser-Meily JM, Ket JC, et al. Caregiver-mediated exercises for improving outcomes after stroke. Cochrane Database Syst Rev. 2016.

8. Lindley RI, Anderson CS, Billot L, Forster A, Hackett ML, Harvey LA, et al. Family-led rehabilitation after stroke in India (ATTEND): a randomised controlled trial. Lancet. 2017;390:588-599.

9. Lawler K, Taylor NF, Shields N. Involving family members in physiotherapy for older people transitioning from hospital to the community: a qualitative analysis. Disabil Rehabil. 2015:37:2061-2069.

10. Lawler K, Shields N, Taylor NF. Training family to assist with physiotherapy for older people transitioning from hospital to the community: a pilot randomized controlled trial. Clin Rehabil. In press, accepted $3^{\text {rd }}$ May 2019.

11. Thorne S. Interpretive description: qualitative research for applied practice. 2 nd ed. NewYork: Routledge; 2016.

12. Tong A, Sainsbury P, Craig J. Consolidated criteria for reporting qualitative research (COREQ): a 32-item checklist for interviews and focus groups. Int J Qual Health Care. 2007; 19:349-357.

13. Liamputtong P. Qualitative Research Methods, 4th ed. South Melbourne: Oxford University Press; 2013.

14. Johnson R, Waterfield J. Making words count: the value of qualitative research. Physiother Res Int. 2004;9:121-131.

15. Shenton AK. Strategies for ensuring trustworthiness in qualitative research projects. Educ Inf. 2004;22:63-75.

16. Tobin GA, Begley CM. Methodological rigour within a qualitative framework. J Adv Nurs. 2004;48:388-396.

17. McCormack B, McCance TV. Development of a framework for person-centred nursing. I Adv Nurs. 2006:56:472-479.

18. Clissett P, Porock D, Harwood RH, Gladman JR. The challenges of achieving personcentred care in acute hospitals: a qualitative study of people with dementia and their families. Int J Nurs Stud. 2013;50:1495-1503.

19. Puurveen G, Cooke H, Gill R, Baumbusch J. A seat at the table: the positioning of families during care conferences in nursing homes. Gerontologist. 2018.

20. Haines KJ. Engaging families in rehabilitation of people who are critically ill: an underutilized resource. Phys Ther. 2018;98:737-744.

21. Lawler K, Taylor NF, Shields N. Outcomes after caregiver-provided speech and language or other allied health therapy: a systematic review. Arch Phys Med Rehabil. 2013:94:1139-1160.

22. McCusker J, Yaffe M, Lambert SD, Cole M, de Raad M, Belzile E, et al. Unmet needs of family caregivers of hospitalized older adults preparing for discharge home. Chronic Illn. 2018: 1742395318789467.

23. Cleary SL, Taylor NF, Dodd KJ, Shields N. A qualitative evaluation of an aerobic exercise program for young people with cerebral palsy in specialist schools. Dev Neurorehabil. 2017:20:339-346.

24. Taylor JS, DeMers SM, Vig EK, Borson S. The disappearing subject: exclusion of people with cognitive impairment and dementia from geriatrics research. J Am Geriatr Soc. 2012:60:413-419. 